\title{
Experimental study of the near-field impact of an oyster table on the flow
}

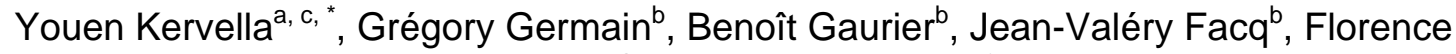 \\ Cayocca $^{\mathrm{a}}$ and Patrick Lesueur ${ }^{\mathrm{c}}$
}

\author{
a IFREMER, DYNECO/PHYSED, Centre de Brest, BP 70, 29280 Plouzané, France \\ b IFREMER, ERT/HO, Centre de Boulogne, 150 quai Gambetta, BP 699, 62321 Boulogne-sur-Mer, France \\ c Laboratoire M2C Université de Caen-Basse Normandie, CNRS/INSU UMR 6143, 2-4 rue des Tilleuls, 14000
} Caen, France

\section{*: Corresponding author : Youen Kervella, Tel.: +33 298224760 , email address : Youen.Kervella@ifremer.fr}

\begin{abstract}
:
Oyster farming structures are artificial obstacles which disturb tidal flow and wave propagation. These effects can induce modifications of erosion and sedimentation patterns, turbidity changes, local silting up and can be threatening for the shellfish farming itself. The understanding of the impact of these structures in terms of hydrodynamics and sediment dynamics in the far-field, i.e. at the scale of a bay, is a very challenging task.

In order to investigate the far-field impact, it is very important to understand in the first place all the changes which occur at a smaller scale, i.e. at the scale of a single table for a farm consisting of oyster tables made of metallic wire structures on which porous bags of oysters are laid. This work is carried out through the idealized representation of the in-situ flow in a free surface flume tank. The flow characteristics around the overall structure are determined from velocity measurements obtained by laser velocimetry. The results highlight an asymmetric development of the boundary layers which suggest the existence of preferential areas for silting up and suspended matter fragmentation under the table.
\end{abstract}

Keywords: Oyster table; Flume; Laser Doppler Velocimetry; Particle Image Velocimetry; Boundary layer; Roughness length; Sediment dynamics 


\section{Introduction}

Oyster farming took off in France in the middle of the nineteenth century with the first thoughts about oyster exploitation and preservation methods by the pioneers De Bon, Coste \& Michelet (www.ostrea.com).

Nowadays, four different farming techniques are used by the French oyster farmers: (1) "on the ground farming", where oysters are simply spread on the tidal flat and picked up during low tide; (2) "deep water farming", where oysters are spread on the ground too, and harvested by a dredge; (3) "suspended farming", where oysters are suspended on ropes, particularly used in the southern France, and (4) the most widely used technique, "elevated farming", which is the most adapted to coasts open to waves and currents. In this case, farms whose dimension can be several squared kilometres, consist of a set of rows of iron wire "tables" which are $100 \mathrm{~m}$ long by $1 \mathrm{~m}$ wide (figure 1). Oysters are locked up in meshed plastic bags attached to these tables.

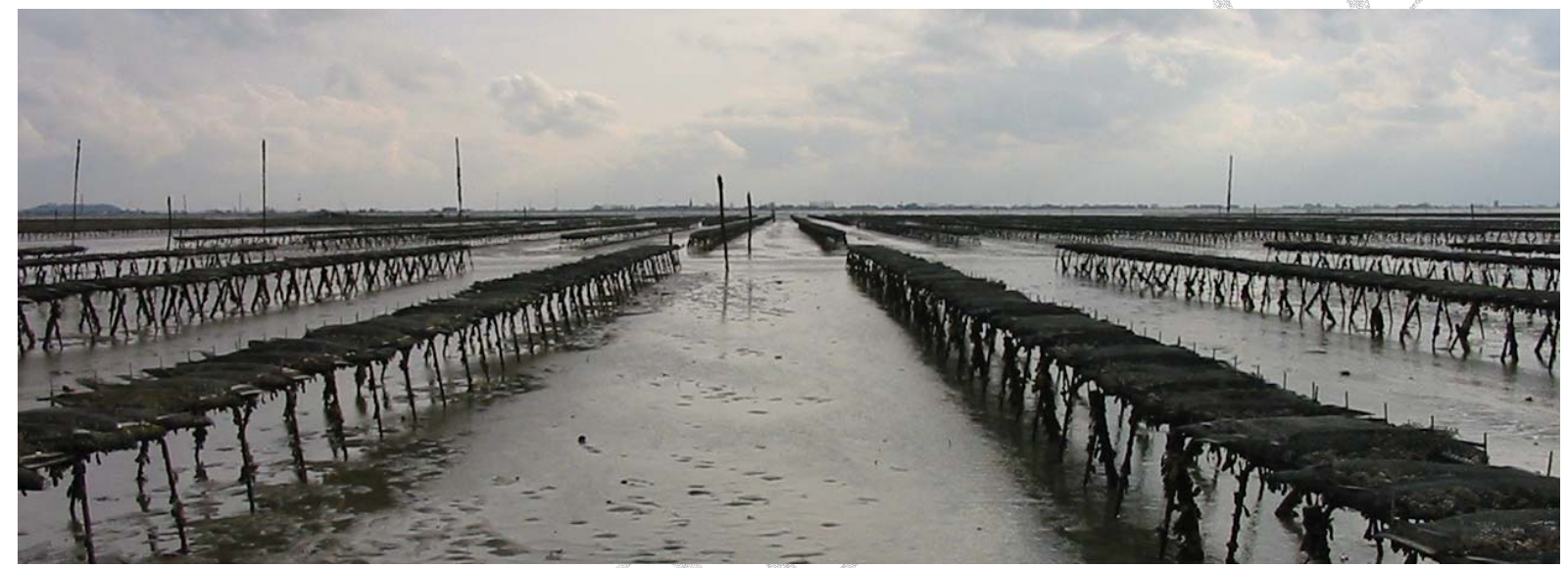

Figure 1: oyster farm in the Mont Saint-Michel Bay

The latter farming technique leads to better quality oysters and increases the productive capacity thanks to reduced losses. However, shortly after the farm installation, an increase in the bed level by sediment deposits has been observed around the structures. This effect could be inherent in this elevated farming technique where oyster tables could induce a decrease in velocity and a deviation of the tidal flow, a local "agitation" weakening and a flow canalization [22]. Sediment deposits under the oyster tables could therefore be protected from erosion, which would explain the observed increase in bed level under the tables. These phenomena are directly or indirectly responsible for mortality events $[14,17]$. These observations have therefore prevailed to a massive oyster farms reorganization since the early seventies in the Mont Saint-Michel Bay [1].

Numerical studies were carried out in order to estimate the morpho-sedimentary effects of oyster or mussel posts $[19,21]$ but were never really validated.

Cayocca [4] introduced the effects of mussel farms on flow circulation and sediment dynamics into a numerical model by increasing the hydraulic roughness used for velocity computations at the location of mussels structures. This study opens a way of modelling mussel or oyster structures implantation but needs to be validated and particularly, the local hydrodynamic processes need to be more accurately described.

Some studies were carried out in flume tanks: Bouma [3] studied spatial flow and sedimentation patterns within patches of epibenthic structures; Plew [16] used vertical rough cylinders in a flume tank in order to investigate the impact of long-lines mussel farms on the flow. Other studies were also carried out for biological motivations: Lundquist and Pilditch [12] performed experiments in a flume tank that mimics water movement near the seafloor to give an indication of flow speeds that result in transport of bivalves. The impact of oyster 
tables on the wave pattern and on the bottom shear stress was estimated by Guizien [8] with a few restrictions: tables were simply modelled by horizontal solid plates, for normal incidence only and without currents. To our knowledge, no other experimental study has been carried out on the interaction between oyster tables and their hydrodynamic and sedimentological environment.

Since the beginning of the eighties, measurement devices have greatly benefited from the emergence of high performance optic and acoustic sensors. These new devices allow high frequency field measurements of waves, currents and turbidity $[11,29,20,5,2,6,7,27,24$, 4]. Nevertheless, apart from some recent field studies $[9,10]$, no deployment focuses on the impact of oyster farming on hydrodynamics.

The present paper describes the experimental study undertaken to determine the impact of an oyster table on the flow, in order to understand fluid/structure interaction effects, particularly in terms of sediment dynamics. Flume tank experiments considered here allow a perfect control of the environmental parameters in order to facilitate the physical understanding of the flow around the overall structure. A specific oyster table model was developed to allow collecting data on the flow by Laser Doppler Velocimetry (LDV) and Particle Image Velocimetry (PIV) techniques.

First, in the results sections, velocity maps are produced around the table which underline boundary layers developments and areas of flow decrease in speed. Then, in the discussion section, the impact of an oyster table on hydrodynamics and on sediment dynamics are both investigated: velocity profiles are used in order to determine table-induced and bottominduced shear stresses; maps of turbulent kinetic energy and Kolmogorov microscale are examined in order to localize areas of flocculation or fragmentation. These data will be used to validate numerical studies which will be described in a future paper.

\section{Experimental device}

\subsection{Experimental setup}

The experimental study took place in the IFREMER (French Research Institute for Exploitation of Sea) free surface flume tank in Boulogne-sur-Mer, France. The flume tank

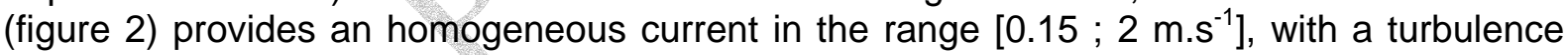
rate lower than $5 \%$. The tank working section is $18 \mathrm{~m}$ long, $4 \mathrm{~m}$ wide and $2 \mathrm{~m}$ deep, with transparent $8 \mathrm{~m} \times 2 \mathrm{~m}$ side windows for direct observation. 

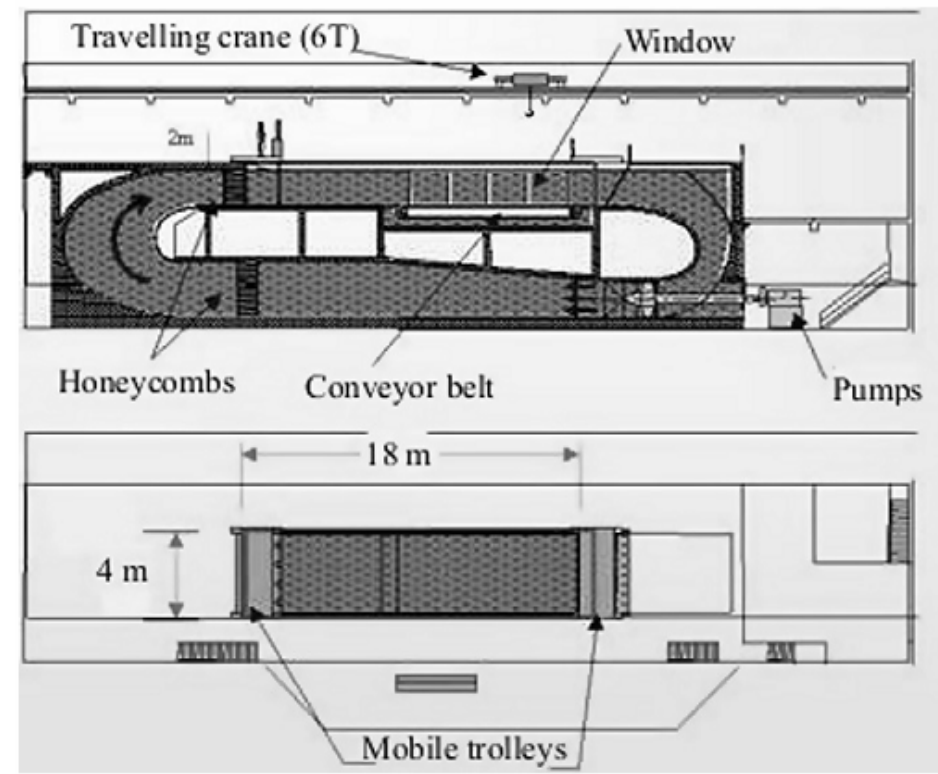

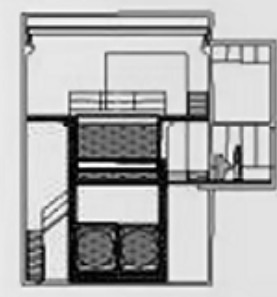

Characteristics:

Working section: Length: $18 \mathrm{~m}$ Width: $4 \mathrm{~m}$ Height: $2 \mathrm{~m}$

Capacity: $700 \mathrm{~m}^{3}$

Fluid velocity: 0.06 to $2.1 \mathrm{~m} / \mathrm{s}$

Figure 2: IFREMER facility.

In the field, an oyster table is typically $100 \mathrm{~m}$ long, $1 \mathrm{~m}$ wide and $0.7 \mathrm{~m}$ high; a good understanding of the sharp current-table interactions droves the choice of a 1/2 scaled model according to Froude similarity. Representing the whole table lengthwise would have required a much greater scale. However, effects of the table length on the flow pattern were investigated through the use of 2 experimental tables of $3.6 \mathrm{~m}$ and $7.2 \mathrm{~m}$ long. These dimensions were chosen so as to allow future oblique orientations in the tank. The oyster table model was made of $8 \mathrm{~mm}$ diameter galvanized iron rod. The oyster bags were manufactured with the same plastic nets as used in the field, but with a $7 \mathrm{~mm}$ meshes (half as large as in the field), while the size ratio between reality and experiments was preserved. Photos and dimensions of the model are given in figure 3 . The bags were filled with real pebbles used to simulate oysters. Cylindrical holes were cut out in the middle of few bags in order to allow laser measurements under the table. Note that oyster net structures are not able to fluctuate laterally.

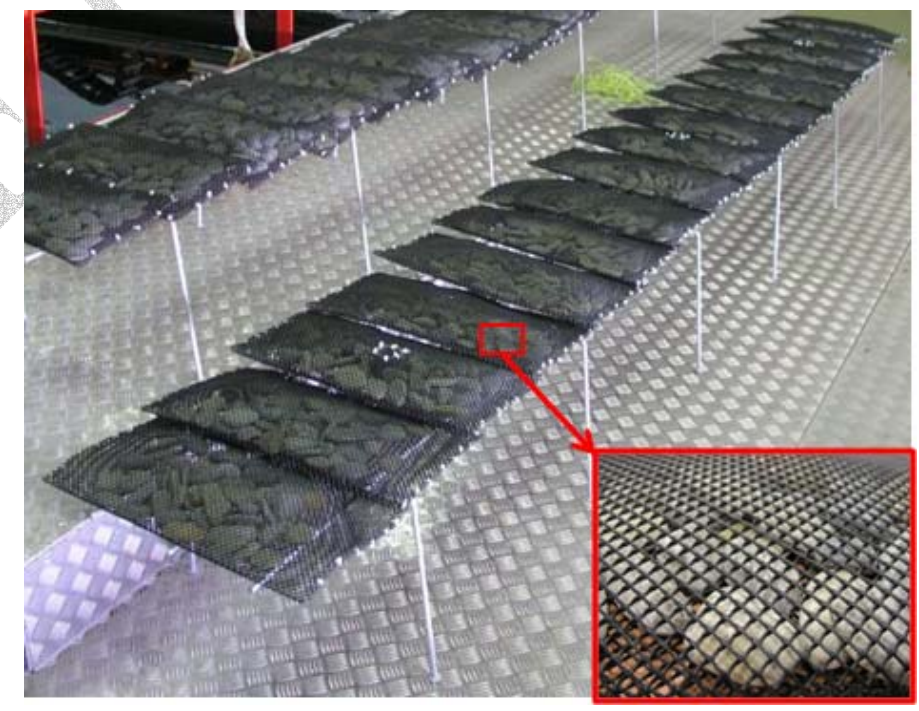




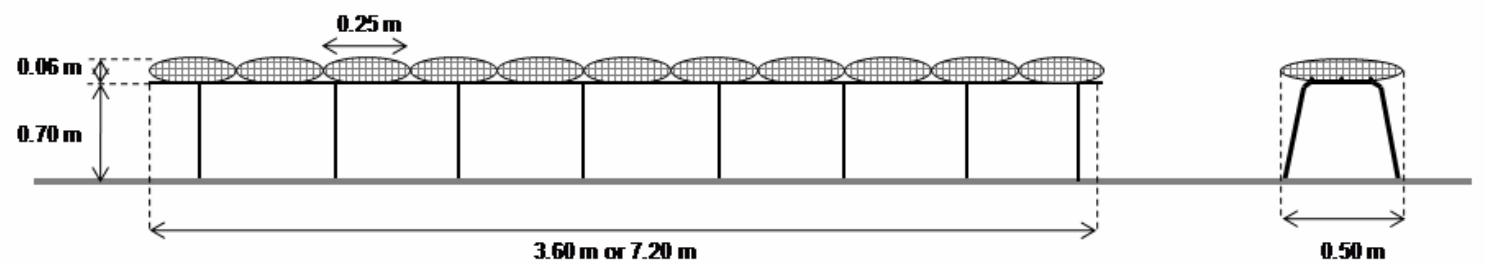

\section{Figure 3: Oyster table model}

According to in-situ measurements [10], maximum velocities recorded in a macro-tidal environment within oysters structures are of the order of $0.4 \mathrm{~m} . \mathrm{s}^{-1}$ at $5 \mathrm{~cm}$ from the bottom. In order to reproduce this magnitude in the flume, water flow with a scaled velocity of $0.28 \mathrm{~m} . \mathrm{s}^{-1}$ was generated at a $2.5 \mathrm{~cm}$ level from the bottom by the propellers, which means a velocity of $0.5 \mathrm{~m} . \mathrm{s}^{-1}$ in the whole water column. In both geometrical cases, i.e. with a $3.6 \mathrm{~m}$ in length table or with a $7.2 \mathrm{~m}$ in length table, the flow is turbulent. Reynolds numbers respectively equal to $1.810^{6}$ and $3.610^{6}$. The $2 \mathrm{~m}$ water depth used for these tests corresponds to an intermediate value encounter in the field within oyster farms.

For a clear localisation of the velocity fields that will be described in various planes, a global frame of reference $(O, x, y, z)$ is chosen. The origin is set at the middle of the upstream table side, just under the first bag (figure 4). Ox is the in-line axis, Oy the transverse axis and $\mathrm{Oz}$ the vertical axis.

\subsection{Instrumentation}

Two non-intrusive measurement devices are used to characterize the flow in the vicinity of the table:

$>$ a two-component Laser Doppler Velocimeter for local measurements,

$>$ a two-component Particle Image Velocimeter for global information on the flow.

LDV is a laser-based method used to measure the flow velocity at a given point, thanks to Doppler Effect. The laser beam generator emits two pair of beams, one for each velocity component being measured, which intersect at a known distance from the probe. When two coherent, collimated laser beams intersect, they form an interference fringe pattern. The intersection location defines the measurement region. The spacing between interference fringes is a known function of the laser wavelength and the separation angle between the two laser beams. Small tracer particles are used to follow the fluid flow through the measurement region by means of laser light reflection (when passed through a fringe). The seeding particles used for our experiments are $15 \mu \mathrm{m}$ diameter silver particles. The velocity can be calculated from the reflection frequency and the spacing between interference fringes. The available LDV device allows to measure two velocity components thanks to two wavelengths (514.5 nm and $488 \mathrm{~nm}$ ) as described in Pichot [15]. The velocity components are measured along the $x$ and $y$ directions.

A particular feature of the LDV measurements is that the number of data recorded in a given time window is strongly dependent on the local seeding conditions: measurements are only possible when a particle moves across the measurement volume. Some regions therefore allowed high frequency acquisitions (exceeding $35 \mathrm{~Hz}$ ); whereas close to the walls or near recirculating zones, the acquisition rate falls to very low values (lower than $5 \mathrm{~Hz}$ ). In order to achieve as the most homogeneous sampling possible, an inhibit method was used and data was recorded under time control rather than sample length control. This technique allowed to obtain a sample length never exceeding 100 seconds (which is an order of magnitude larger than the time scale of the flow fluctuations) with a number of data points per sample never 
exceeding 3500. The long time span allows an accurate estimate of average values for velocity and turbulence intensity.

Nowadays, PIV is the most used velocity measurement technique in fluid-mechanics. This success results from the fact that it provides information over the flow field, at many points simultaneously. The PIV is a very simple non-intrusive technique. The fluid is seeded with tracer particles (the same as for LDV) and the region under investigation is illuminated by a laser. A picture of the illuminated region is captured and a second picture is taken a short time period later. The analysis of these images yields the particles displacement [26]. The velocities are obtained by dividing the distance by the elapsed time between laser pulses, and an instantaneous velocity vector map is produced.

A two-chamber Gemini PIV Nid-Yag $2 \times 120 \mathrm{~mJ}$ pulsed laser at $15 \mathrm{~Hz}$ is used for the experiments. The camera is a Hi-sense, $1280 \times 1024$ pixels $^{2}$, with a focal lens length of 60 $\mathrm{mm}$ with a filter wavelength of $3 \mathrm{~nm}$. The measurement plane is typically $284 \times 227 \mathrm{~mm}^{2}$. A cross-correlation then produces a vector map from one image map pair. The interrogation area is $16 * 16$ pixels $^{2}$ with an horizontal and vertical overlap of $25 \%$. A velocity-range validation rejects vectors outside a certain range given by: $-0.2<U<0.7 \mathrm{~m} . \mathrm{s}^{-1}$ and $-0.3<\mathrm{V}<$ $0.3 \mathrm{~m} . \mathrm{s}^{-1}$, where $U$ and $V$ are respectively the in-line velocity and the transverse velocity. Finally, an average filter substitutes each vector with the uniformly weighted average of the vectors in a neighbourhood of a size of $3 \times 3$ vectors. Instantaneous velocity fields are obtained and generally, a series of 80 instantaneous measurements are statistically averaged to get the mean velocity field.

\subsection{Experimental protocol}

These experiments focus on the hydrodynamic phenomena relevant to investigate sediment dynamics. Its aims are therefore:

$>$ to estimate the effect of the table length

$>$ to understand mechanisms which take place around the oyster table (boundary layer development, wake, ...)

$>$ to emphasize some areas of flow acceleration or deceleration, particularly near the bottom.

Six vertical measuring profiles (each profile consists of 17 measurement locations) or maps normal to the flow (each map consists of 50 measurement locations) were investigated with the LDV technique on the $3.60 \mathrm{~m}$ table and 10 more maps or profiles on the $7.20 \mathrm{~m}$ table. Each map is described by 1 horizontal profile and 3 vertical ones (figure 4). Moreover, 6 vertical planes were sampled with the PIV technique along the $7.20 \mathrm{~m}$ table longitudinal axis. In order to compare both measurement approaches, LDV profiles were spatially averaged while the records from both systems were processed using the same averaging time lag. Tables were aligned with upstream flow and so were most of the field observations, i.e. incidence effects were not investigated. 


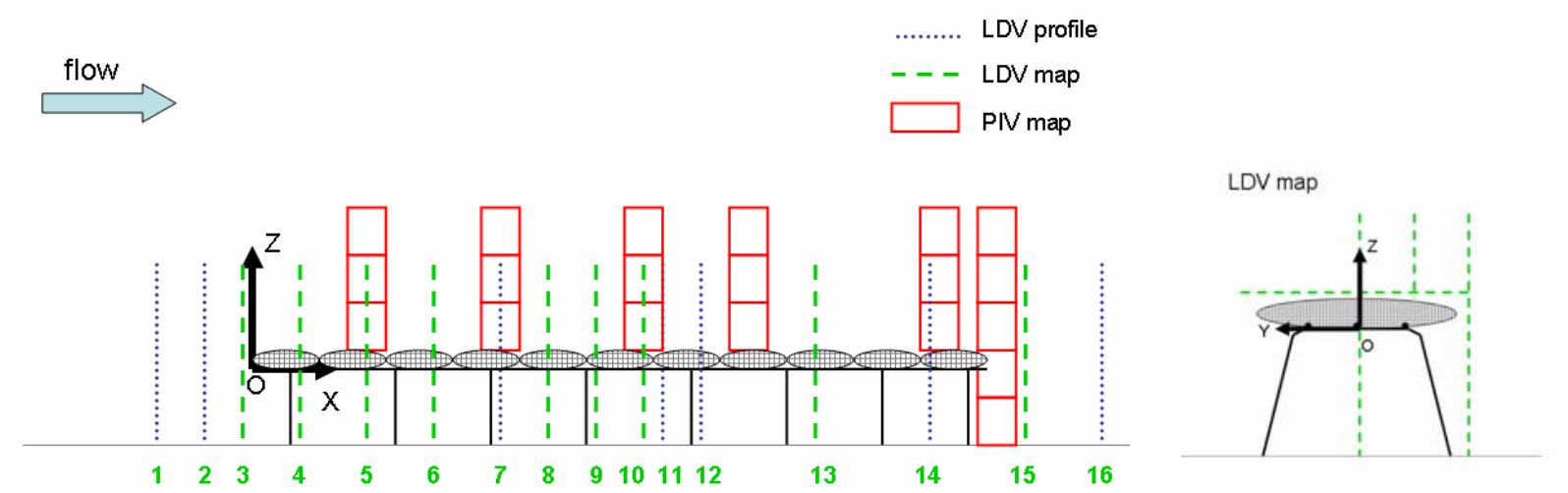

Figure 4: Geometry of the $7.20 \mathrm{~m}$ table model and locations of the measurement profiles.

\section{Results}

LDV velocities along the 16 monitoring profiles are interpolated in order to generate $2 \mathrm{D}$ velocity plots as shown on figures 5 to 16 . The extrapolation between two profiles is validated from PIV results. This technique is less accurate (in term of frequency) than the LDV one but provides a global overview of the flow field at a given time. Figure 5 shows the good agreement between these two techniques at the trailing edge of the table (the most turbulent area of the flow around the table) as well as everywhere above the structure. Note that all velocity fields or profiles are presented with a scale in $\mathrm{m} . \mathrm{s}^{-1}$.
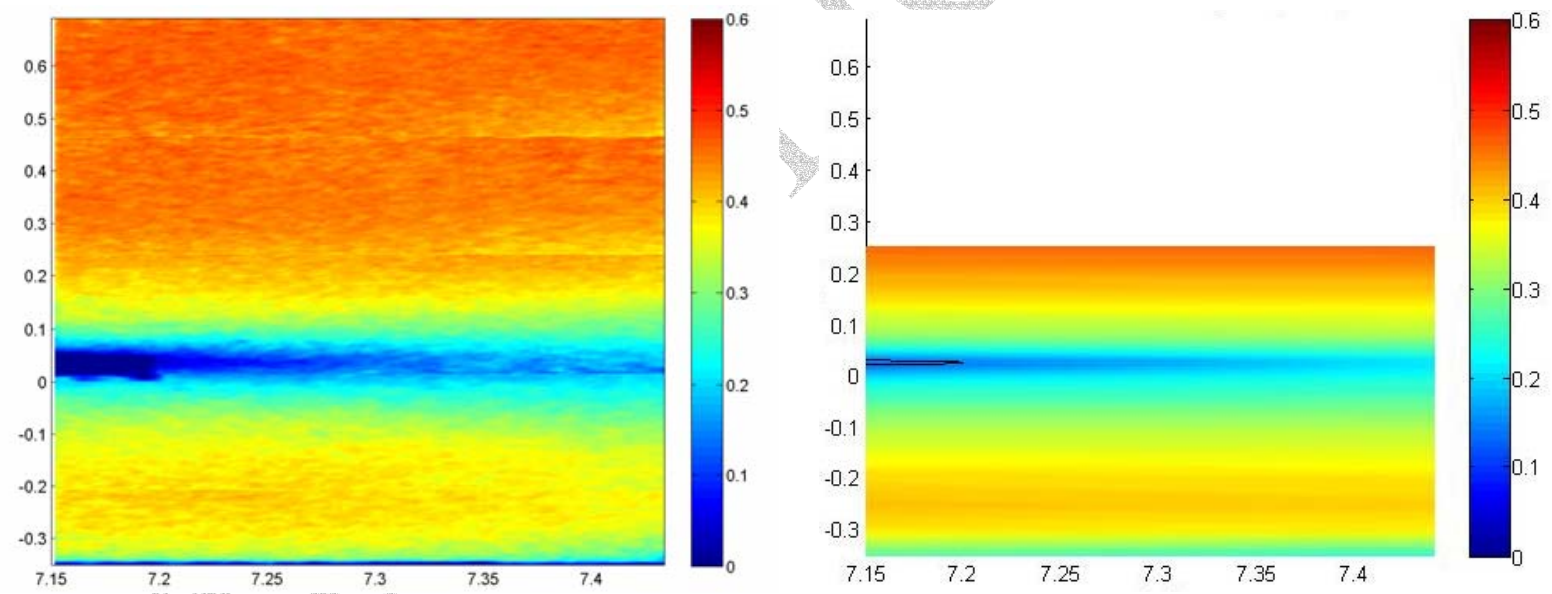

Figure 5: Longitudinal velocities at the trailing edge of the $7.2 \mathrm{~m}$ table (Oxz plane) obtained by PIV (on the left) and LDV (on the right, after interpolation between profiles at $x=6.65 \mathrm{~m}$ and at $x=7.65 \mathrm{~m}$ ).

The $1 / 2$ scale is applied to the table width but not to its length, which should have been of $50 \mathrm{~m}$ in order to reach a geometric similarity compared to the field. Because of the important model shortening (3.6/50 and 7.2/50), we first investigated the validity of the following hypothesis: is the global flow around a $1 / 2$ scale table of less than 10 meters in length representative of the flow around a 50 meters length table?

Figure 6 shows the velocity field around the 3.6 and $7.2 \mathrm{~m}$ length tables and the boundary layers development. There are 3 boundary layers around the structure: one above the table called "the upper boundary layer" in the next sections, one below the table and one next to the bottom. The comparison of the two fields shows that the complete development of the upper boundary layer occurs after more than $4 \mathrm{~m}$. The thickness of the well developed upper boundary layer is for this configuration one table height $(\sim 0.3 \mathrm{~m})$. This value is $150 \%$ higher 
than for a smooth wall boundary layer (the boundary layer theory predicts in this case a thickness close to $0.12 \mathrm{~m}$ to recover $99 \%$ of the free stream velocity) ; this is due to the presence of rough oyster bags. The boundary layer below the $7.2 \mathrm{~m}$ length table never reaches a full development and continues to increase until it meets the bottom boundary layer. How far this phenomenon will extend? Will the flow speed decrease to zero at a given? This point is very important in terms of sediment dynamics: a very low flow velocity will lead into a preferential area of silting up.

The effect of the table length was investigated by means of LDV measurements, on a relatively short table as compared to the field equivalent because of the limited size. It is difficult to extrapolate the results to longer tables, even if the upper boundary layer of the table is well established: we do not know how high the interactions between the lower boundary layer and the bottom one can be. A way to further investigate length effects is therefore to numerically model a table of realistic dimensions in order to understand and to quantify the velocity decrease under oyster tables.
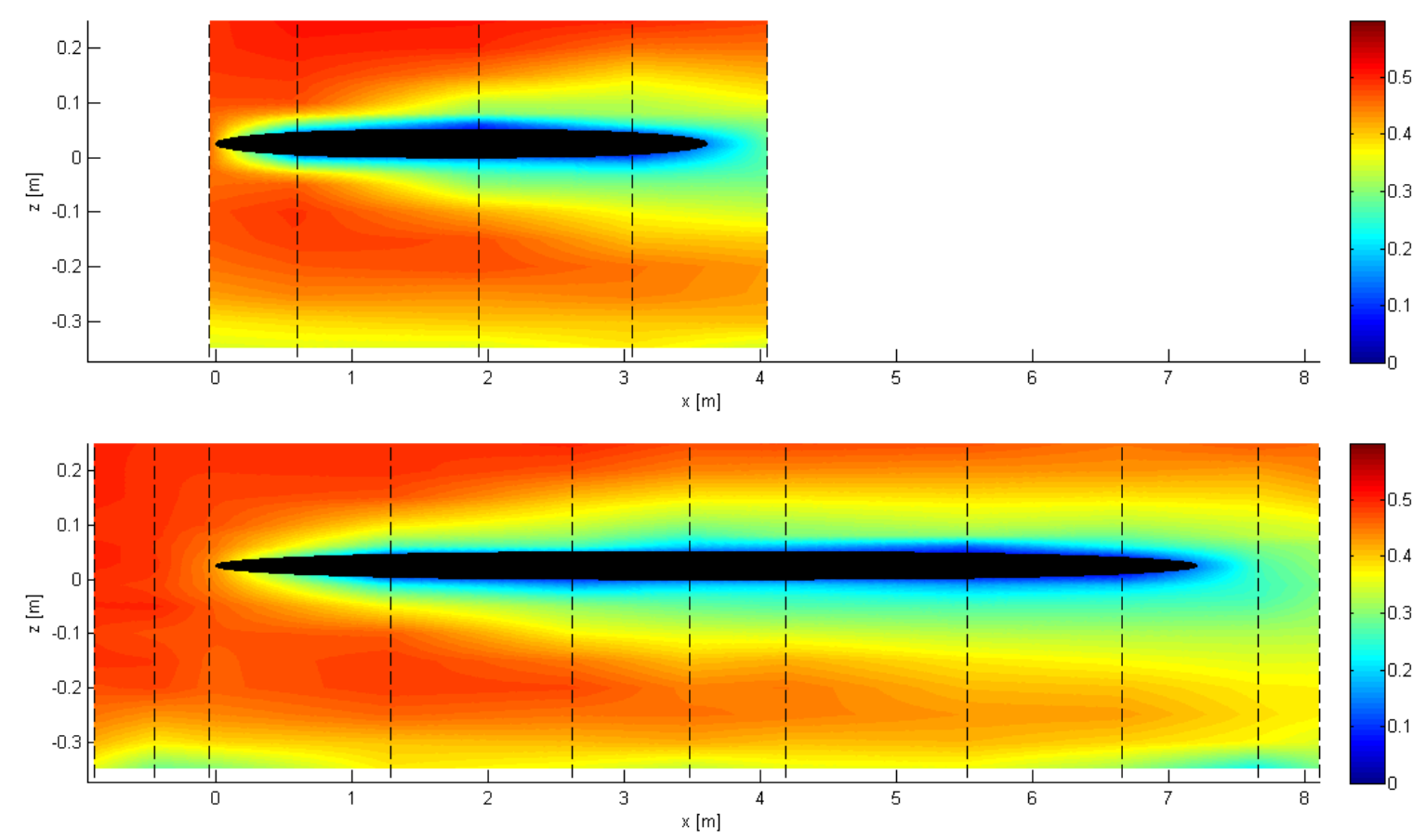

Figure 6: Longitudinal velocities (Ux) on the median plane, for a $3.60 \mathrm{~m}$ table (upper part of the graph) and a $7.20 \mathrm{~m}$ table (lower part). Dotted lines represent LDV measurement locations.

Figure 7 displays the transverse velocities in the vertical median plane (Oxz). The expected symmetry of the flow along the $x$ direction is satisfied. The red part on the map (less than 4 $\%$ of the inline upstream velocity) comes from the hole made at this location $(x=1.28 \mathrm{~m})$ to allow measurements under the table. 


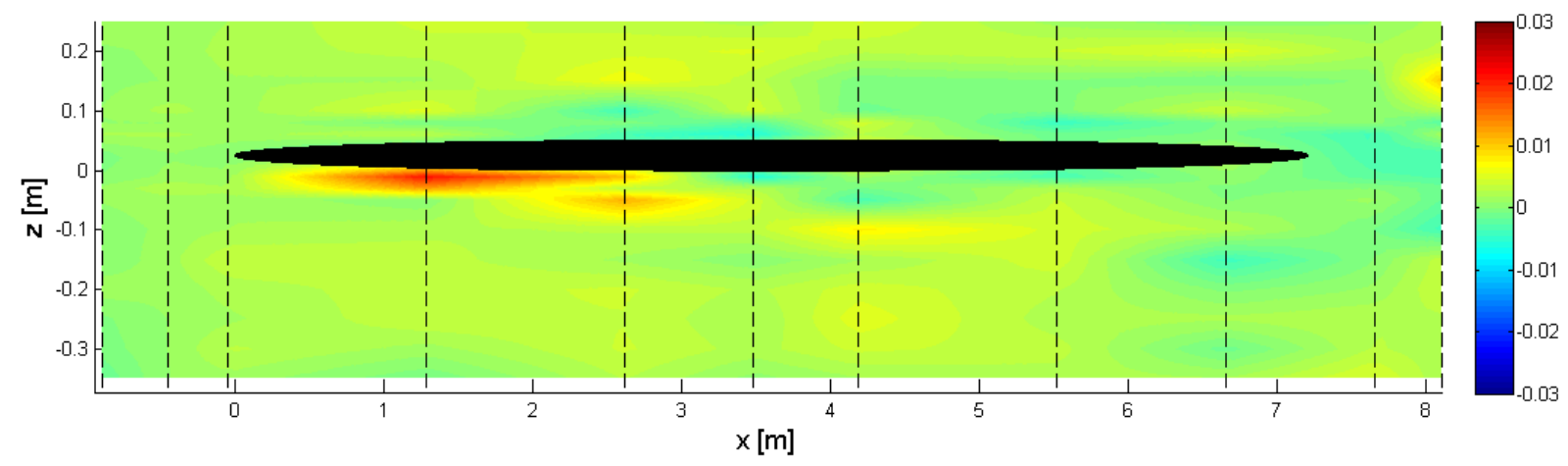

Figure 7: Transverse velocities (Uy) on the median plan of the $7.2 \mathrm{~m}$ table. Dotted lines represent LDV measurement locations.

Figure 8 displays the longitudinal and transverse velocity components at 2 locations respectively $45 \mathrm{~cm}$ upstream and $45 \mathrm{~cm}$ downstream the $7.20 \mathrm{~m}$ table. While the upstream velocity components are relatively smooth, the characteristics of the flow downstream the table vary in an irregular pattern. It is a characteristic signature of turbulence. The decrease in flow speed is significant too (50\% of attenuation).
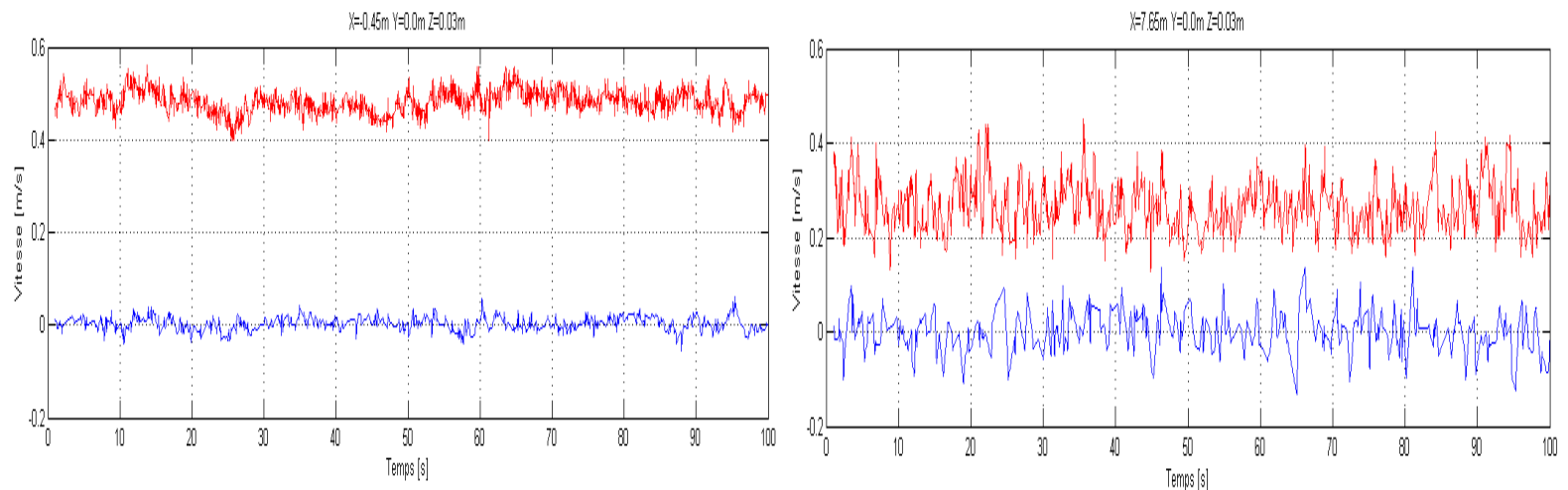

Figure 8: $L D V$ measurements for $U x$ (red line) and $U y$ (blue line) at the location $x=-0,45 \mathrm{~m}$ and $x=7,65 \mathrm{~m}, 3 \mathrm{~cm}$ above the $7.20 \mathrm{~m}$ table during $100 \mathrm{~s}$.

LDV velocity vectors are drawn on figure 9 . Behind the trailing edge of the table, the two velocity profiles coalesce into one profile in the wake. The magnitude of the depression in the velocity curve is directly connected to the drag on the table. In the case of a flow around a smooth plate at zero incidence and far from the bottom, the drag coefficient of the velocity profile in the wake is calculated by using the momentum equation [18]. We do not attempt to do this calculation due to the complex shape of the oyster bags and the interactions between the structure and the bottom.

Velocity profiles in the other vertical planes, respectively in the planes $y=0.15 \mathrm{~m}$ and $y=0.30 \mathrm{~m}$ (figure 9) give additional information on wake evolution and decrease in speed in $3 \mathrm{D}$. 


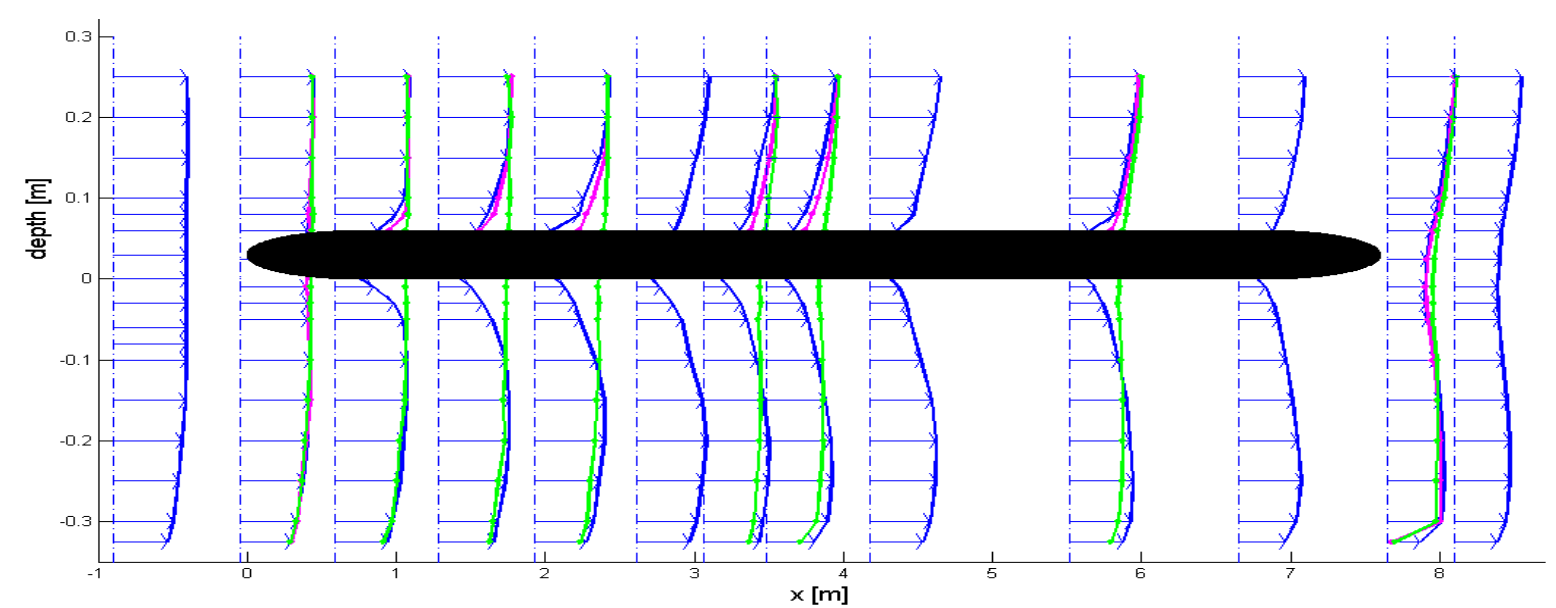

Figure 9: Velocity vectors at each profile on the vertical median plane (in blue), on the plane $y=0.15 \mathrm{~m}$ (in pink) and on the plane $y=0.30 \mathrm{~m}$ (in green), for a $7.20 \mathrm{~m}$ table.

The broadening of this wake is clear in the plane $y=0.30 \mathrm{~m}$, i.e. $5 \mathrm{~cm}$ outside the edge of the oyster bags. At the table level (altitude $z=0$ ), the decrease in speed increases with the distance (wake broadening). The same graph highlights an important velocity decrease from under the table down to the ground level, which can be due to the presence of the table supports. In fact, this velocity decrease is higher in the plane $y=0.30 \mathrm{~m}$ than in the median plane.

In the plane $y=0.15 \mathrm{~m}$, the wake development is quite similar to the development on the median plane but within a smaller velocity decrease close to the oyster bags.

This wake broadening is confirmed by the horizontal LDV cartography which was carried out $3 \mathrm{~cm}$ above the oyster bags (figure 10). The wake expands according to the transverse component and some areas exhibit very large decelerations: up to $50 \%$ of velocity decrease above the table after half a table length.
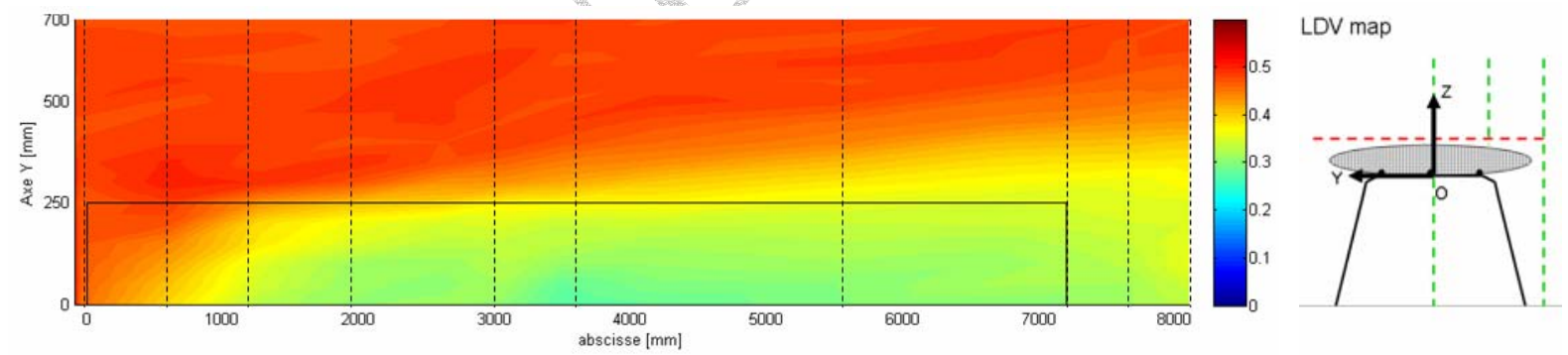

Figure 10: Longitudinal velocities (Ux) on the horizontal plane, in $z=0.08 \mathrm{~m}$, for a $7.20 \mathrm{~m}$ table. Dotted lines represent measurement locations.

In order to fully understand the wake development around the overall structure, LDV longitudinal velocities cartographies along the table (YZ planes) are investigated (figure 11). On the first three planes (planes 4 to 6 , see figure 4 for the location of the planes), there is a high velocity decrease close to the oyster bags in the area where the wake expends. The boundary layers below the table and above the bottom do not meet in the median plan (the wake exhibits a conical shape under the table). On the last plane (plane 15), just behind the table, the velocity attenuation is above $20 \%$ everywhere from the bottom to the table. 


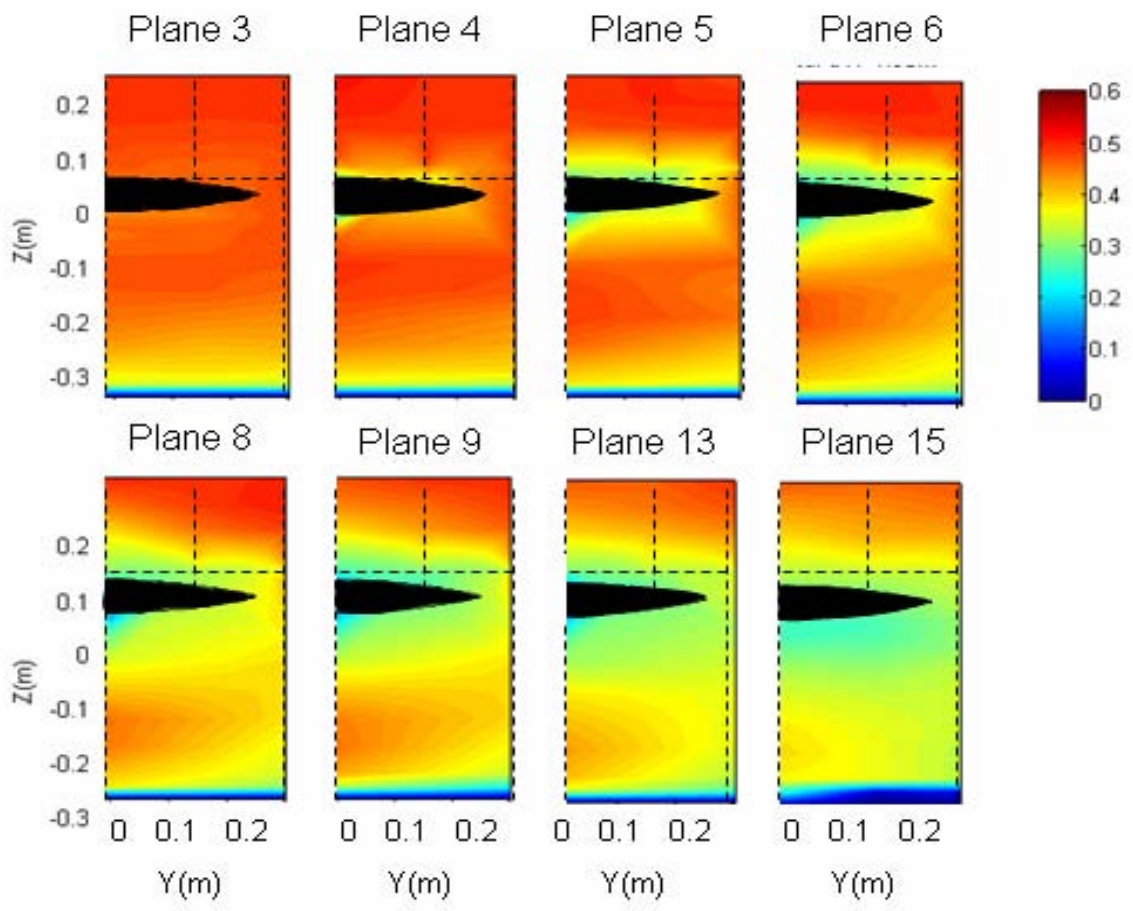

Figure 11: Longitudinal velocity maps along the 7,2 $m$ table. Dotted lines represent measurement locations.

Figure 12 shows a three dimensional representation of the $0.4 \mathrm{~m} \cdot \mathrm{s}^{-1}$ isovelocity, which corresponds to a $20 \%$ decrease in velocities. The development of the table upper boundary layer is clearly seen after half a table length, where the thickness of the upper boundary layer reaches a stable value. This graph also highlights the merge of the lower boundary layer and the bottom one, which results in a strong velocity decrease. The wakes conical shape under the table is confirmed. The table legs could play an important part in the fluid/structure interaction process and could explain this conical shape.

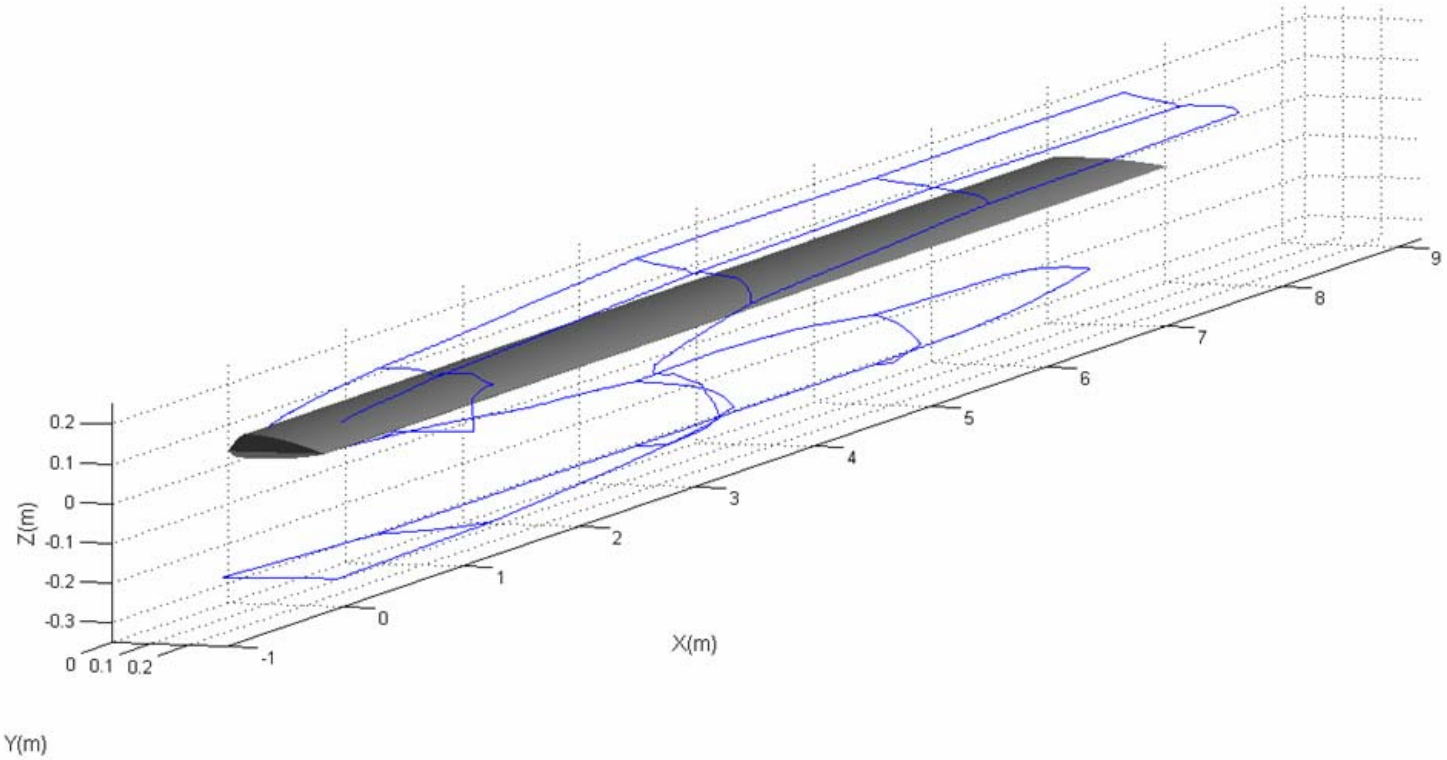

Figure 12: 3D representation of the $0.4 \mathrm{~m} / \mathrm{s}$ isovelocity contour around the $7.20 \mathrm{~m}$ table. 


\section{Discussions}

The main purpose of this study is to determine the local impact of an oyster table on the hydrodynamics on the one hand, i.e. in terms of circulation modifications and current dissipation, and on sediment dynamics on the other hand, i.e. in terms of turbulence near the bottom and sediment motion.

\subsection{Hydrodynamics: the local impact of an oyster table on the flow}

\subsubsection{Trajectories around the table:}

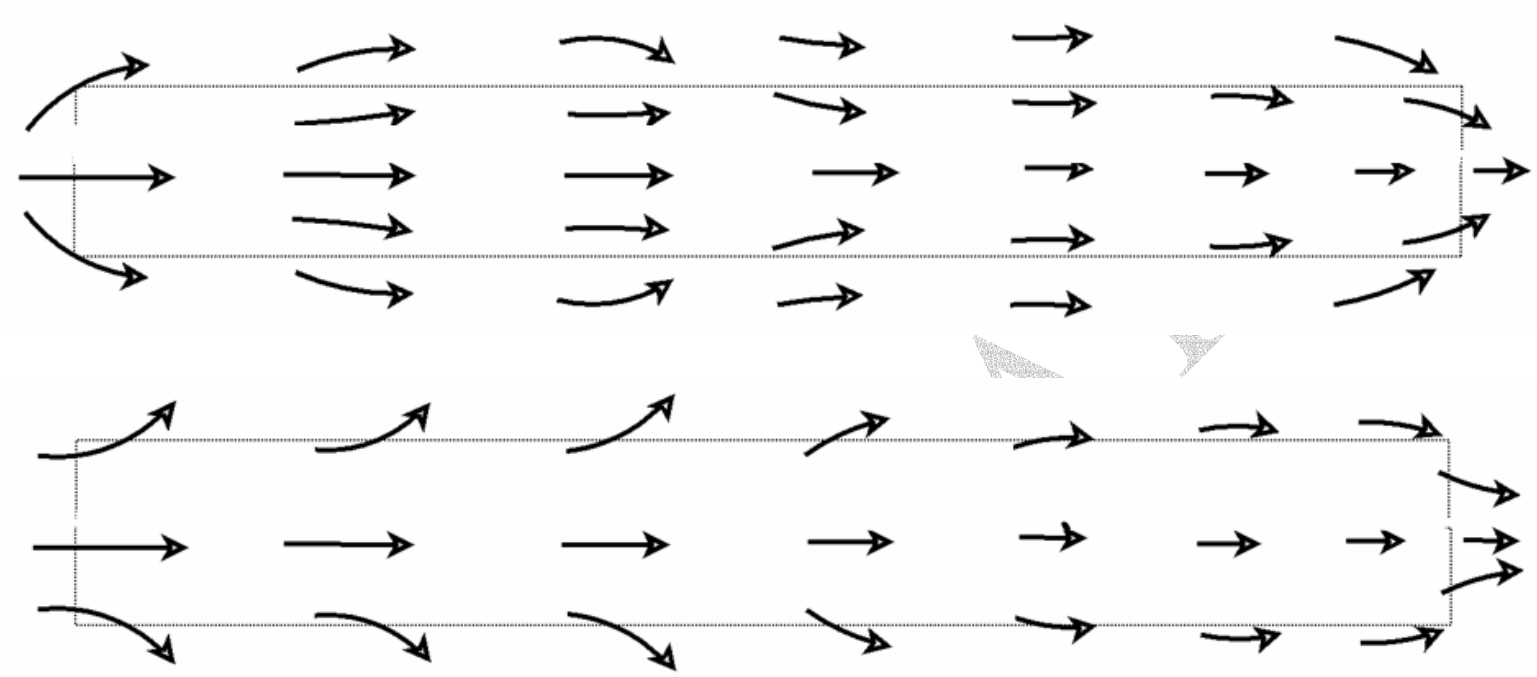

Figure 13: Velocity vectors above the table (top) and under the table (bottom). Interpretative sketch deduced from the available LDV measurements. For sake of comprehension, transverse component of the velocity is exaggerated.

The mean flow trajectories in the table near field are summed up on figure 13. Above the table, the flow skirts round the leading edge of the table, comes back to the main direction and finally converges at the trailing edge of the table. The flow slows down along the table while the upper table boundary layer develops.

Under the table, the merging of the lower table and the bottom boundary layer induces areas of strongly reduced flow velocities. The main flow diverges through the table lateral edges in the first meters and then comes back to the main direction. The impact of an oyster table on the flow trajectories is asymmetric (different above and under the table), maybe due to table legs and bottom presence under the table.

\subsubsection{Shear stress and dissipation:}

The oyster farm-related drag could be expressed in terms of a Strickler coefficient $k$. The Strickler coefficient is linked to the bottom roughness and is often used in numerical models to compute the friction on the bottom. This section is devoted to the determination of the table-induced and bottom-induced shear stresses and the Strickler coefficients within and without the oyster structure.

In order to determine the roughness length $z_{0}$, the shear velocity and then the shear stress, the velocity profiles obtained by the LDV method are used (figure 14). Each profile is split into three parts: one above the table, another one under the table and the last one near the 
bottom. For each part, an hypothesis of a well-established flow is done and the velocity profile is given by the Von Karman-Prandlt equation [23]:

$$
\begin{array}{r}
u(z)=\frac{u^{*}}{\kappa} \ln \left(\frac{z}{z_{0}}\right) \quad \text { where: } \mathrm{u}^{*} \text { is the friction velocity (or shear velocity) } \\
\mathrm{z}_{0} \text { is the roughness length } \\
\mathrm{\kappa} \text { is the Von Karman's constant }(\kappa=0.4)
\end{array}
$$
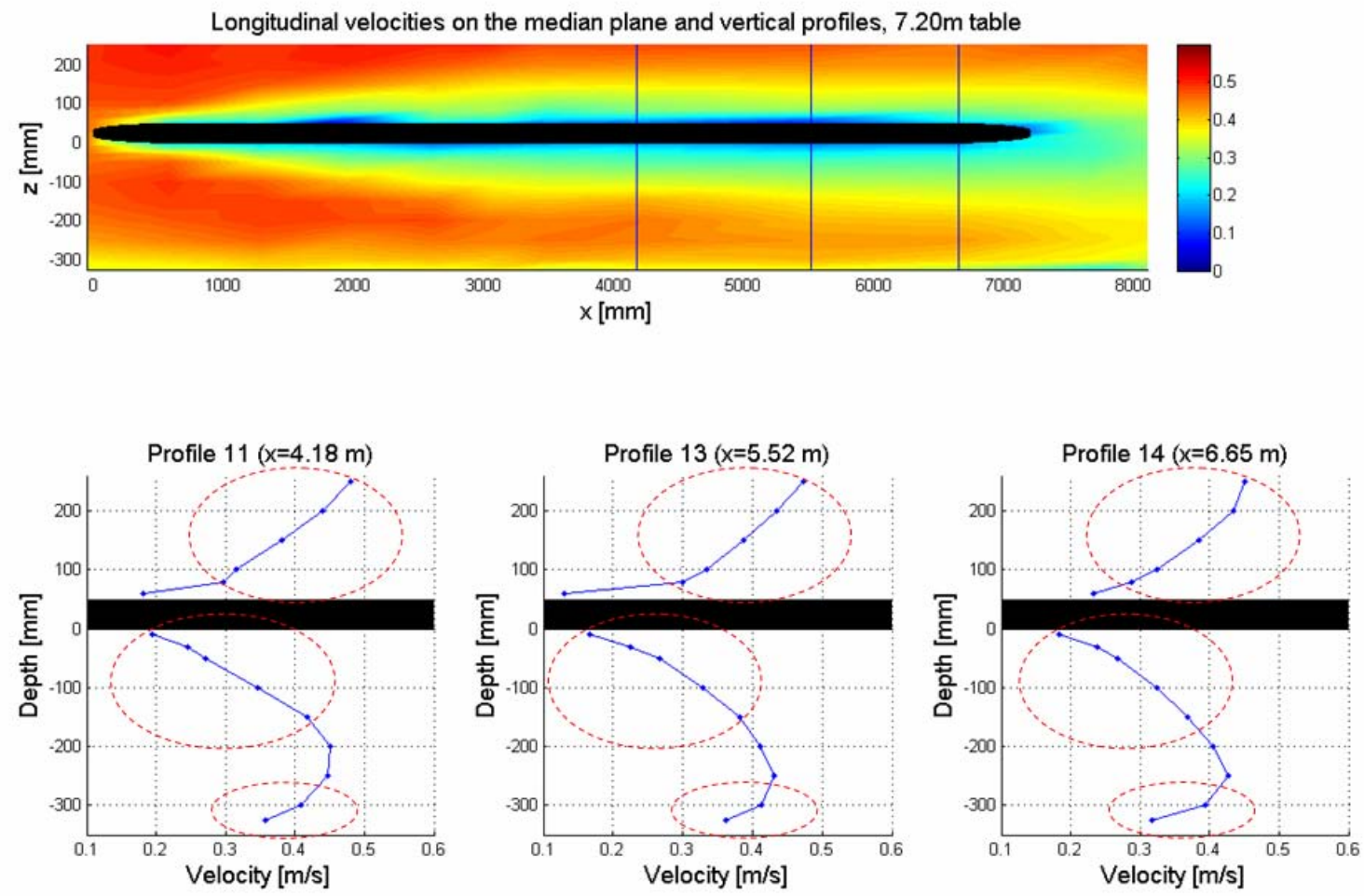

Figure 14: Velocity profiles along the $7.20 \mathrm{~m}$ table.

Two areas of calculation are distinguished: an area upstream the table where the parameters are computed without the influence of the structure, and another area along the table, within the influence of the structure. For the latter area, the total shear stress on the whole water column is computed for each profile by summing up the local shear stresses (table 1).

A linear regression in semi-log coordinates is performed on each part of the experimental velocity profiles and gives $z_{0}$ and $u^{\star}$. The shear stress $\mathrm{T}$ is computed from $\mathrm{T}=\rho \mathrm{u}^{\star 2}$.

\begin{tabular}{|c|c|c|c|}
\hline & $\begin{array}{c}\text { Profile 11 } \\
(\mathrm{x}=4.18 \mathrm{~m})\end{array}$ & $\begin{array}{c}\text { Profile 13 } \\
(\mathrm{x}=5.52 \mathrm{~m})\end{array}$ & $\begin{array}{c}\text { Profile 14 } \\
(\mathrm{x}=6.65 \mathrm{~m})\end{array}$ \\
\hline $\begin{array}{c}\mathrm{Z}_{0} \\
\text { above the table }(\mathrm{m})\end{array}$ & 0.012 & 0.011 & 0.010 \\
\hline $\begin{array}{c}\mathrm{U}^{\star} \\
\text { above the table }(\mathrm{m} / \mathrm{s})\end{array}$ & 0.064 & 0.061 & 0.057 \\
\hline $\begin{array}{c}\mathrm{T} \\
\text { above the table }(\mathrm{N})\end{array}$ & 4.12 & 3.69 & 3.27 \\
\hline $\begin{array}{c}\mathrm{Z}_{0} \\
\text { under the table }(\mathrm{m})\end{array}$ & 0.003 & 0.003 & 0.003 \\
\hline $\begin{array}{c}\mathrm{u}^{\star} \\
\text { under the table }(\mathrm{m} / \mathrm{s})\end{array}$ & 0.033 & 0.032 & 0.027 \\
\hline $\begin{array}{c}\mathrm{T} \\
\text { under the table }(\mathrm{N})\end{array}$ & 1.08 & 1.02 & 0.75 \\
\hline
\end{tabular}




\begin{tabular}{|c|c|c|c|}
\hline $\begin{array}{c}\mathrm{Z}_{0} \\
\text { near the bottom }(\mathrm{m})\end{array}$ & 0.0002 & 0.0002 & 0.0015 \\
\hline $\begin{array}{c}\mathrm{u}^{*} \\
\text { near the bottom }(\mathrm{m} / \mathrm{s})\end{array}$ & 0.029 & 0.029 & 0.045 \\
\hline $\begin{array}{c}\mathrm{T} \\
\text { near the bottom }(\mathrm{N})\end{array}$ & 0.83 & 0.85 & 2 \\
\hline $\mathrm{T}$ total $(\mathrm{N})$ & 6.03 & 5.55 & 6.02 \\
\hline
\end{tabular}

Table 1: roughness length $\mathrm{z}_{0}$, shear velocity $u^{*}$ and shear stresses $\mathrm{T}$ in profiles 11, 13 and 14 .

The different values of $z_{0}$ and $\mathrm{T}$ above and under the table could be explain by different geometries: above the table, there is a succession of bags which can be compared to sand ridges, and under the table the profile of the bags is flatter due to the presence of horizontal iron bars.

The velocity profile upstream the table (in $\mathrm{x}=-0.90 \mathrm{~m}$ ) gives a roughness length of $3.10^{-5} \mathrm{~m}$ and a bottom shear stress of $0.52 \mathrm{~N}$.

The presence of the oyster table entails a total shear stress ten times higher than the shear stress without the structure.

According to $\tau=\frac{\rho g \overline{u^{2}}}{k^{2} h^{1 / 3}}$, the Strickler coefficient $\mathrm{k}$ is often used to parameterize coastal hydrodynamic models current dissipation. Oyster farming areas should therefore be characterized by a Strickler coefficient $\sqrt{ } 10$ smaller than without oyster farms.

Nevertheless this value is overestimated since in an oyster farm there are rows of oyster tables and alley without tables too (figure 1). Cayocca et al. [4] used a Strickler coefficient divided by 1.8 for mussel farms areas modelling. In previous physical experiments [21], it was shown that the Strickler coefficient is divided by 1.4 to 2.5 in mussel farms.

\subsection{Sediment dynamics close to an oyster table}

\subsubsection{Bottom shear stress:}

Near-bed velocities and shear stresses both drive the sediment particles motion [26]. The bottom shear stress upstream the oyster table is $0.52 \mathrm{~N}$. Due to the presence of the structure and in spite of the flow slower velocities, the bottom shear stress $\mathrm{T}$ increases under the table: it reaches $0.8 \mathrm{~N}$ for the 2 firsts profiles and $2 \mathrm{~N}$ for the last one. Since the sediment motion is initiated by a critical value of this bottom shear stress $\mathrm{T}$, this increase of $\mathrm{T}$ is significant. Nevertheless, these values must be examined with a critical eye: the linear regression on the velocity profile close to the bottom is based on two points only. The value of $2 \mathrm{~N}$, at a location where there is an important interaction between the boundary layers, is not very reliable. This attempt of bottom shear stress calculation need therefore to be validated by direct measurements of turbulent velocity fluctuations and Reynolds shear stresses $\left.\left(\rho<u_{x}{ }^{\prime} u_{z}{ }^{\prime}\right\rangle\right)$ in future studies.

The generalization of this increase of the bottom shear stress is difficult due to the length of the model table compared to an oyster table in the field.

\subsubsection{Turbulence and suspended matter:}

Since oysters locally produce fine particles it is very important to determine turbulence in the water column under the oyster table. Via flocculation and fragmentation processes, turbulence controls the size and the settling velocity of this suspended matter and so affects sediment transport and deposition.

The energy of turbulent dissipation is investigated by a turbulent-closure model $\mathrm{K}-\varepsilon$, function of the Turbulent Kinetic Energy (TKE) $K$ and the dissipation rate $\varepsilon$ : 


$$
K=\frac{1}{2}\left({\overline{u_{x}^{\prime}}}^{2}+{\overline{u_{y}^{\prime}}}^{2}+{\overline{u_{z}^{\prime}}}^{2}\right) \quad \text { and } \quad \varepsilon=C_{v} \frac{K^{\frac{3}{2}}}{l}
$$

where $u_{x}^{\prime}, u_{y}^{\prime}$ and $u_{z}^{\prime}$ are the fluctuating parts of the velocity, $C_{v}$ is a dimensionless constant equal to 0.09 [13] and $I$ is the mixing length, here equal to 0.25 (oyster bag characteristic length).

LDV measurements only give access to the horizontal velocity components of the flow. The previous figures suggest that the flow has the same way of skirting round the table along the $y$-direction and along the $z$-direction. So, the assumption is made that the fluctuating part of the vertical velocity component is equal to the fluctuating part of the transverse velocity component, i.e. $u_{z}^{\prime}=u_{y}^{\prime}$.

Under this hypothesis, the TKE distribution around the overall table in the median plane is calculated and shown on figure 15. TKE values decrease away from the structure, with maximum values of $0.006 \mathrm{~m}^{2} . \mathrm{s}^{-2}$ close to the oyster bags and to the bottom. "table-induced" TKE does not propagate to the bed: the oyster table has an impact on the water column, in terms of turbulence, but not directly on the bed.

TKE values measured in-situ close to the bed without oyster farms are presented on figure 15. These values, measured by means of an Acoustic Doppler Velocimeter (ADV), are estimated using velocity variances filtered from the wave contribution [28]. They are of the same order as our experimental ones near the table. Thus, it affects in the same manner the lower part of the water column. So, in an oyster farming area, bed roughness and oyster structures both contribute to turbulence in the water column, despite the fact that the oyster structure does not directly affect bed sediments. But figure 15 results suggest that the interaction between the bottom boundary layer and the table-induced one has an impact on the rate of turbulence close to the bottom. Note that the TKE values upstream the table, i.e. the background level of turbulence, are negligible opposite to table-induced values.
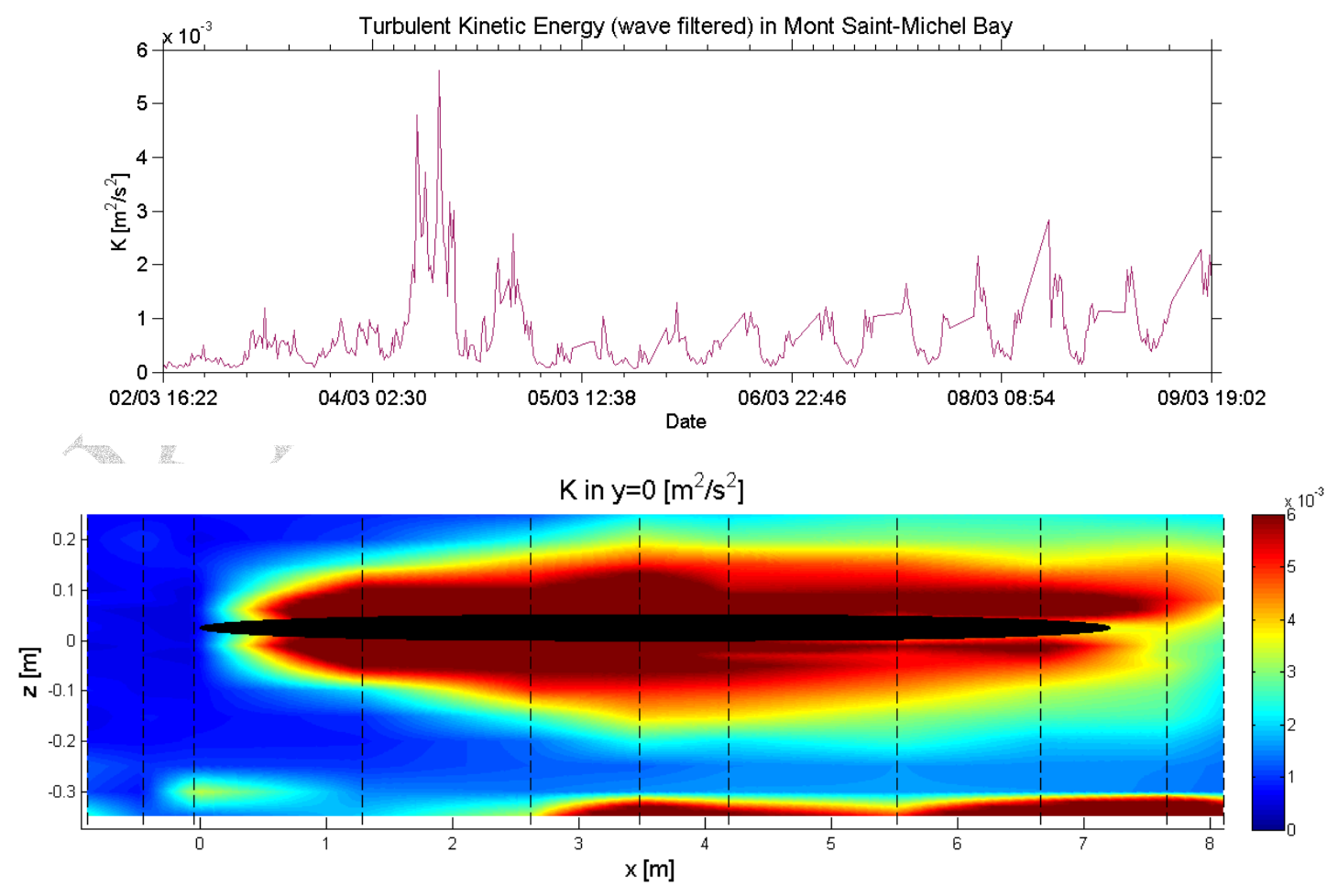

Figure 15: in-situ Turbulent Kinetic Energy $\left(T K E, \mathrm{~m}^{2} / \mathrm{s}^{2}\right)$ measurements in Mont Saint-Michel Bay during winter 2008 (top). Vertical map in the plane $y=0$ of the TKE $\left(\mathrm{m}^{2} / \mathrm{s}^{2}\right)$ along the 7.20 $m$ table (bottom). Dotted lines represent measurement locations. 
The TKE produced by the table can also affect flocculation and fragmentation processes of suspended particulate matter. In order to evaluate some preferential area of flocculation or fragmentation, the Kolmogorov microscale is calculated:

$\eta=\left(\frac{v^{3}}{\varepsilon}\right)^{\frac{1}{4}} \quad$ where $\mathrm{v}$ is the kinematic viscosity of water.

The Kolmogorov microscale characterizes the smallest turbulent structures of the flow. At this scale, vortices dissipate kinetic energy in viscous form.

Figure 16 displays the map of Kolmogorov microscale in the median plane. The oyster table modifies the flow in the whole water column. Around the structure, a preferential area of fragmentation is created (area in blue). Below the table, this area is half an oyster table height from the oyster bags. In this fragmentation area, conditions are not favourable to sediment flocculation and the size of particles will not exceed $300 \mu \mathrm{m}$, i.e. the size of the microscale.

Flocculation processes are very complex due to the suspended particulate matter rates and organic contents, more particularly in the case of oyster faeces production. More precise studies are needed to go further on this point.

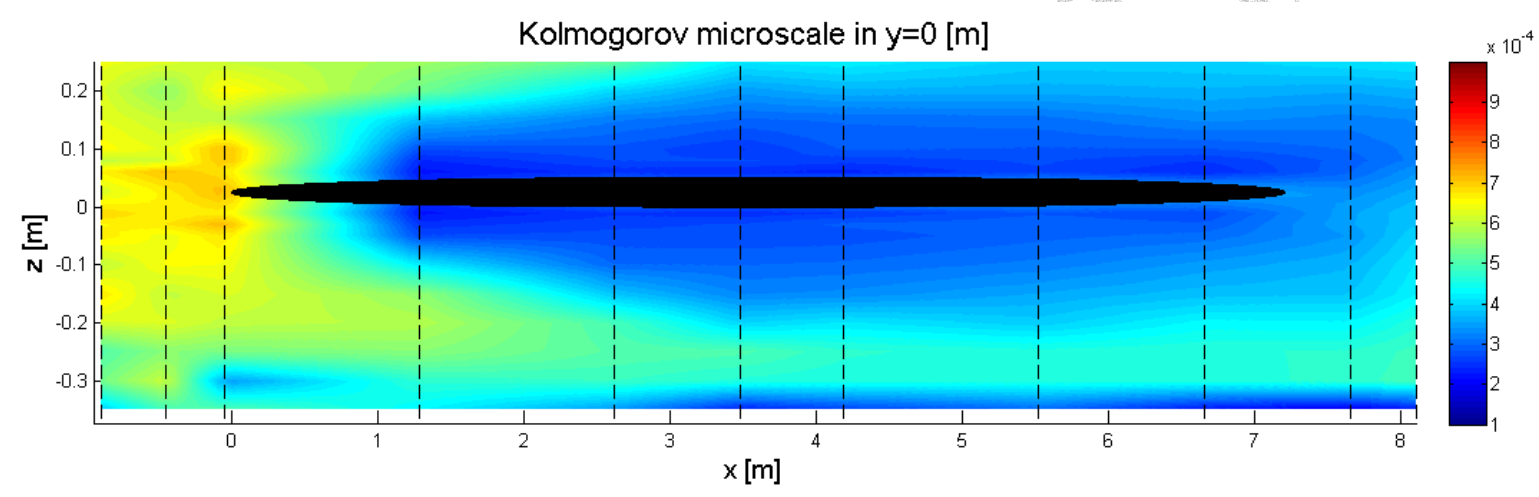

Figure 16: Vertical map at $y=0$ of the Kolmogorov microscale $(\eta, m)$ along the $7.20 \mathrm{~m}$ table. Dotted lines represent measurement locations.

\section{Conclusions}

The near-field impact of an oyster table on flow has been investigated in a flume tank. These experimental results highlight an asymmetric development of boundary layers around the overall structure, with some important areas of flow slowing down, particularly under the table. When the bed shear velocity exceeds the particles fall velocity, the sediment particles can be lifted and may be transported in suspension. That is what happens in the field where currents are sufficiently strong to transport sediments in suspension. But this study results highlight the fact that oyster farms can locally modify the strength of the currents by creating new boundary layers and so on can modify sediment transport and can cause preferential locations of silting up.

Moreover a significant part of the water column is affected by the presence of the structure; a large fragmentation area is created just below the oyster bags, according to the Kolmogorov microscale distribution. An oyster structure will therefore locally play a role in the behaviour of suspended matter.

The roughness length, the shear velocity and the shear stress were calculated with and without the oyster table. The total shear stress within the structure is ten times higher than the shear stress without the structure. The presence of oyster tables is very important for current dissipation, more particularly for a wide extension modelling, at the scale of a bay. 
These results also show the effect of the table length. We can see especially differences in the establishment of the upper table boundary layer and in the interactions between the lower table and the bottom boundary layers. Nevertheless, numerical studies are needed to improve this effect of the table length with a modelling of more realistic lengths.

So, the present study will be used for the calibration of a computational fluid dynamics (CFD) model within the same configuration as the experimental one. After validation, this CFD model could be extended to several directions of the flow towards table alignment, and to several tables' configurations too.

Future experimental studies on incidence effects and for different upstream velocities will be carried out and will help the development of this CFD model.

A specific study to evaluate the possibility to use this model at higher scales will be of great interest to give information at the scale of an oyster farm.

From a wider (applied) fluid mechanics point of view, this kind of study on the impact of structures on shallow water flows is highly advisable. The experimental modelling of such underwater structures (oyster and mussel farms, submerged vegetation, ..) allows the calibration of numerical models for hydrodynamics or sediment dynamics by providing an adapted Strickler coefficient; especially as the recent development of renewable energy systems in coastal environments, like offshore wind turbine farms.

\section{Acknowledgements}

The authors wish to thank the Région Basse-Normandie for its financial support of this work carried out in the flume tank of IFREMER.

\section{References}

[1] Bahé, S., 2003. Conchyliculture et dynamique morpho-sédimentaire en Baie du Mont Saint-Michel. Mémoire de Master, EPHE, pp. 161.

[2] Bassoulet, P., Le Hir, P., Gouleau, D., and Robert, S., 2000. Sediment transport over an intertidal mudflat: field investigations and estimation of fluxes within the "Baie de MarennesOléron" (France), Continental Shelf Research 20 (2000), pp. 1635-1653.

[3] Bouma, T.J., van Duren, L.A., Temmerman, S., Claverie, T., Blanco-Garcia, A., Ysebaert, T. and Herman, P.M.J., 2007. Spatial flow and sedimentation patterns within patches of epibenthic structures: Combining field, flume and modelling experiments, Continental Shelf Research 27 , pp. 1020-1045.

[4] Cayocca, F., Bassoulet, P., Le Hir, P., Jestin, H. and Cann, P., 2008. Sedimentary processes in a shellfish farming environment, Mont Saint-Michel Bay, France, Sediment and ecohydraulics, Proceedings INTERCOH 2005, pp. 431-446.

[5] Christie, M.C., Dyer, K.R. and Turner, P., 1999. Sediment flux and bed-level measurements from a macrotidal mudflat. Estuarine, Coastal and Shelf Science, volume 49, pp. 667-688.

[6] Deloffre, J., Lafite, R., Lesueur, P., Lesourd, S., Verney, R. and Guézennec, L., 2005. Sedimentary processes on an intertidal mudflat in the upper macrotidal Seine estuary, France. Estuarine, Coastal and Shelf Science, volume 64, pp. 710-720.

[7] Deloffre, J., Verney, R., Lafite, R., Lesueur, P., Lesourd, S. and Cundy, A.B., 2007. Sedimentation on intertidal mudflats in the lower part of macrotidal estuaries: Sedimentation rhythms and their preservation. Marine Geology, volume 241, pp. 19-32.

[8] Guizien, K., 1996. Etude du champ de vitesses sous une et plusieurs plaques soumises à la houle et immergées près du fond , mémoire de DEA, 1996.

[9] Kervella (a), S., Kervella, Y., Severe storm effects on stability of cohesive sediments in oyster farming area, within the « Baie de Marennes-Oléron » (France), to be submitted. 
[10] Kervella (b), Y., Cayocca, F., Verney, R.., Jestin, H., Bassoullet, P., Cann, P., Le Hir, P. and Lesueur P.. The impact of oyster structures on hydrodynamics in a macro- tidal environment. To be submitted.

[11] Kirby, R., Bleakley, R.J., Weatherup, S.T.C., Raven, P.J., Donaldson, N.D., 1993. Effect of episodic events on tidal mudflat stability, Armillan Bay, Strangford Lough, Northern Ireland.

[12] Lundquist, C., Pilditch, C., 2006. Shellfish on the move: predicting recovery of coastal habitats. Water \& Atmosphere 14(1): 12-13.

[13] Matsunaga, N., Sugihara, Y., Komatsu, T., Masuda, A., 1999. Quantitative properties of oscillating-grid turbulence in an homogeneous fluid. Fluid dynamics research, volume 25, pp. 147-165.

[14] Nikodic, J., 1981. Dynamique sédimentaire dans la partie occidentale de la baie du Mont-Saint-Michel. université de Nantes Thèse de doctorat.

[15] Pichot, G., Germain, G., Priour, D., 2008. On the experimental study of the flow around a fishing net, European Journal of Mechanics B/Fluids.

[16] Plew, D. R., 2005. The hydrodynamic effects of long-line mussel farms. PhD thesis, University of Canterbury, pp. 330.

[17] Ropert, M., 1999. Caractérisation et déterminisme du développement d'une population de l'annélide tubicole Lanice Conchilega associé à la conchyliculture en Baie des Veys (Baie

[18] Schlichting, 1979, Boundary-layer theory, Mac Graw-Hill Classic Textbook Reissue Series Seventh Edition, pp. 817. ISBN 0-07-055334-3

[19] SeaMER, 2000. Etude d'impact de la restructuration conchylicole en baie du Mont SaintMichel, étude courantologique et sédimentologique, rapport SRC Bretagne Nord, pp. 41.

[20] Silva Jacinto R., Bessineton, Ch., Levoy, F., Védieu, C.H., Lesourd, S., Rousset, H., Benoît, L., Jestin, H., Monfort, O., 1998. Réponse de la vasière Nord aux forçages météoocéaniques. Rapport final du thème Hydrodynamique et Transport Sédimentaire, programme scientifique Seine Aval, avril 1998, pp. 99-111.

[21] SOGREAH, 1986. Amélioration de la mytiliculture dans la Baie de l'Aiguillon. Rapport LCHF.

[22] Sornin, 1981. Processus sédimentaires et biodéposition liés à différents modes de conchyliculture, thèse de l'Institut des Sciences de la Nature de l'Université de Nantes, pp. 188

[23] Soulsby, R.L., 1997. Dynamics of Marine Sands. A Manual for Practical Applications. Thomas Telford, London, 249p.

[24] Tessier, C., 2006. Caractérisation et dynamique des turbidités en zone côtière : l'exemple de la région marine Bretagne Sud, thèse, université Bordeaux-1, pp. 386.

[25] Tonddast-Navaei, A., 2005. Acoustic particle image velocimetry: Development and applications, PhD, Open University, pp. 149.

[26] van Rijn, L. C., 1993. Principles of sediment transport in rivers, estuaries and coastal seas. Aqua Publications. Amsterdam, The Netherlands.

[27] Verney, R., Deloffre, J., Brun-Cottan, J.C., Lafite, R., 2007. The effect of wave-induced turbulence on intertidal mudflats: impact of boat traffic and wind. Continental Shelf Research, volume 27, pp. 594-612.

[28] Verney, R., Brun-Cottan, J.C., Lafite, R., Deloffre, J., Taylor, J.A. 2006. Tidally-induced Shear Stress Variability above Intertidal Mudflats in the Macrotidal Seine Estuary.. Estuaries and Coasts, volume 29, $\mathrm{n}^{\circ} 4$, pp. 653-664.

[29] Whitehouse, R.J.S., Mitchener, H.J., 1998. Observations of the morphodynamic behaviour of an intertidal mudflat at different timescales. In: Black, K.S., Paterson, D.M., Cramp, A. (eds) Sedimentary Processes in the Intertidal Zone. Geological Society, London, Special publication 139, pp. 255-271. 